\title{
Local Variation in Absolute Water Content of Human and Rabbit Eye Lenses Measured by Raman Microspectroscopy
}

\author{
Alex Hulzingat, Annet C. C. Bot f, Frits F. M. de Mul†, \\ GiJs F. J. M. VRENSEN $\ddagger \|$ AND Jan GREve† \\ Twente University of Technology, Faculty of Applied Physics, P.O. Box 217, \\ 7500 AE Enschede, The Netherlands, $\dagger$ and Netherlands Ophthalmic Research Institute, \\ P.O. Box 12141, 1100 AC Amsterdam. The Netherlands $\ddagger$
}

(Received 1 April 1988 and accepted in revised form 7 November 1988)

\begin{abstract}
Raman spectra were obtained from fresh, fixed and sliced rabbit lenses and from human lens slices. For all lenses and lens slices the ratio $R$, defined as the Raman intensity at $3390 \mathrm{~cm}^{-1}$ divided by the Raman intensity at $2935 \mathrm{~cm}^{-1}$, was measured at different locations along the visual and equatorial axis. The ratios $R$ were transformed to absolute water mass percentages by measuring solutions with known protein concentrations. It was shown that fixation and slicing have very little effect on the absolute water content of the lenses. The values obtained for the absolute water content are comparable to values given in literature. It was also shown that the water content in rabbit and human lenses rapidly decreases from the immediate anterior and posterior subsurface region to the deep superficial cortex and is relatively constant in the nucleus. Raman microspectroscopy appears to be a reliable method for the measurement of the absolute water content of small volumes on defined positions in the lens. This can be very useful when analyzing the possible relation between local variations in water content and the occurrence of opacities in the lens.

Key words : cataract; human; lens; rabbit; Raman spectroscopy ; water content.
\end{abstract}

\section{Introduction}

Numerous studies have been devoted to the relationship between water content and translucency of eye lenses. It was proposed that the metabolic activity of the lens is mainly directed towards maintaining normal hydration $(60-65 \%)$ and normal protein synthesis (Lerman, 1984). It was proven that disturbance of the water balance leads to opacification (Maraini and Mangili, 1973). The causal relation between osmotic imbalance and turbidity has been extensively described, e.g. for diabetic cataract (Chylack, Tung and Harding, 1986).

As senile or senescent cataract is a main threat for the lens making up $90 \%$ of all cataracts, the relationship between lenticular hydration and aging is investigated thoroughly (Bours and Födisch, 1986; Bours, Födisch and Hockwin, 1987; Lahm, Lee and Bettelheim, 1985). It was shown that the total water content of normal human lenses decreases with age. Not just the total water content but also the ratio between protein-bound (non-freezable) and bulk (freezable) water is thought to be relevant for the occurrence of opacities (Bettelheim, Ali, White and Chylack, 1986). It was suggested that syneresis, i.e. the transition of bound to bulk water, is a main factor in the aging process of normal lenses leading to opacification (Lahm et al., 1985). Age dependent changes in lenticular water content and local variations in water content have been investigated (McEwan and Farnsworth, 1987). It has been shown that the cortex contains significantly more water than the nucleus.

i| To whom all reprint requests should be addressed.

$0014-4835 / 89 / 040487+10 \$ 03.00 / 0$

(C) 1989 Academic Press Limited 
Moreover, systematic morphological studies of early cataractous aging human lenses (Willekens, Kappelhof and Vrensen, 1988) have shown that opacities first occur in the deep superficial equatorial cortex and that upon progression they extend towards the anterior and posterior poles leaving the nucleus unaffected. This may indicate that the deep superficial cortex is most vulnerable for opacifying insults in the lenticular fibers. It would be interesting to investigate whether cataractous insults, as oxidative stress (Spector, 1984), lead to fiber changes, and consequently to changes in the water content, or that a change in the water content of the superficial cortex is a leading factor in the formation of early cataractous spots. To reach this goal a precise local measurement of water content is a prerequisite.

Water content of eye lenses has been investigated with differential scanning calorimetry (Bettelheim, Christian and Lee, 1982; Nunnari, Williams and Powell, 1986), nuclear magnetic resonance (Racz, Tompa and Pocsik, 1979), dynamic light scattering (Latin et al., 1987) and dry weight determination (Bours and Födisch, 1986 ; Bours et al., 1987). Despite the refinements of these methods and the restriction of the measurements to, e.g. cortical and nuclear parts of the lens, the disadvantage of these methods remains the relatively large volumes necessary for a measurement, i.e. large relative to the cataractous spots.

A non-destructive method with the ability to measure very small volumes $(<10-6$ $\mu 1$ ) is Raman microspectroseopy (Iriyama, Mizuno, Ozaki, Itoh and Matsuzaki, 1982). In studying early cataractous spots $( \pm 1 \mathrm{~mm}$ diameter) with Raman microspectroscopy it can be advantageous to use lens slices instead of intact lenses. In a previous paper (Bot, Huizinga, de Mul, Vrensen and Greve, 1988) the following technical advantages of using lens slices were pointed out.

(i) After irradiating lens slices of old Huorescent human lenses with laser light the fluorescence is reduced so much that Raman spectra can be obtained. Formerly it was thought impossible to record Raman spectra of old human lenses.

(ii) There is no deflection of the laser beam on the lens surface while measuring in the equatorial cortex.

In order to make slices it is necessary to fix the lenses. Paraformaldehyde is used as a fixative. This has very little influence on the Raman spectra. Fixation also has the advantage of extending the time available for Raman analysis, which is especially useful for human lenses

The aim of the present study is to show that Raman analysis is a good method to investigate relative water content of rabbit and human lenses in small position defined volumes. A second goal is to calculate the absolute water content at different locations in rabbit and human lenses.

\section{Materials and Methods}

\section{Raman spectroscopic technique}

All Raman spectra were recorded, as described earlier (Gijsbers et al., 1986), with a SPEX 1877B spectrometer, an EG\&G PAR OMA III multichannel detector, an Olympus BSM metal microscope and a Coherent model 52 Argon-ion laser with Innova tube emitting at $514.5 \mathrm{~nm}$. The effective entrance pupil in the plane of the entrance slit is $100 \times 1500 \mu \mathrm{m}$. Peak frequencies were calibrated in $\mathrm{cm}^{-1}$ by measuring lines of an Argon calibration lamp, using a cubic fit procedure. They are accurate to $\pm 1 \mathrm{~cm}^{-1}$. The sensitivity variation over the multichannel detector range was eliminated by using a correction curve.

Laser power at sample is $25 \mathrm{~mW}$ and resolution is $4 \mathrm{~cm}^{-1}$. Waist diameter, focal depth and 
measured volume for the $20 \times$ objective and $50 \times$ objective are $5 \mu \mathrm{m}, 1.0 \mathrm{~mm}, 170 \times 10^{-3} \mu \mathrm{l}$ and $2 \mu \mathrm{m}, 0 \cdot 1 \mathrm{~mm}, 3 \times 10^{-3} \mu \mathrm{l}$ respectively.

A cuvette containing an intact lens in a phosphate buffered salt solution (PBS), $\mathrm{pH} \mathrm{7.3}$ and osmolarity $310 \mathrm{mOsmol}$, was placed on the translation stage of the microscope. The laser beam was focused on different positions in the lens from the surface to the nucleus along the visual axis. The $180^{\circ}$ scattered Raman light was collected by the microscope objective and focused on the entrance slit of the spectrograph.

Slices were put on an object glass in a drop of PBS to prevent drying. The slice was covered with a $0.17 \mathrm{~mm}$ thick cover glass. A more detailed description of the measuring procedure has been outlined in a previous paper (Bot et al, 1988).

Measurements in the intact lenses were carried out from the surface to $0.5 \mathrm{~mm}$ under the surface with steps of $0.1 \mathrm{~mm}$ with a $50 \times$ objective. With a $20 \times$ objective spectra were recorded from $1 \mathrm{~mm}$ under the surface to the nucleus with steps of $1 \mathrm{~mm}$. The slices were measured with a $50 \times$ objective.

\section{Lens material}

Four rabbit lenses were obtained from two 6-month-old healthy Dutch belted rabbits (2-6 hr post-mortem). Once extracted, Raman spectra of the fresh lenses were measured immediately. After measurement the lenses were fixed during one week in $1 \%$ paraformaldehyde buffered with $0.08 \mathrm{~m}$ cacodylate ( $\mathrm{pH} 7.3,310 \mathrm{mOsmol}$ ). Then again Raman spectra were recorded. Immediately after these measurements slices of $1 \mathrm{~mm}$ were cut along the visual axis with a razor blade and Raman spectra were recorded along the visual axis.

Seven clear human lenses were obtained from donor lenses varying from 3 to $46 \mathrm{yr}$ of age. The lenses were taken out of the eyes 6 to $16 \mathrm{hr}$ post mortem. They were directly fixed in paraformaldehyde. For practical reasons it was not possible to obtain Raman spectra from fresh human donor lenses. Before Raman analysis these lenses were sliced in order to diminish the effect of fluorescence and to have access to the equatorial cortex. For these slices Raman spectra were recorded both along the visual and equatorial axis.

\section{Determination of absolute water content}

We can calculate the absolute water mass percentage from the Raman spectrum. The following symbols are defined:

$P$ : mass percentage of protein

$W$ : mass percentage of water

$m_{p}$ : protein mass in a lens volume

$m_{w}$ : water mass in a lens volume

$I_{p}$ : Raman intensity at $2935 \mathrm{~cm}^{-1}$ due to $\mathrm{CH}$ stretch of protein

$I_{w}$ : Raman intensity at $3390 \mathrm{~cm}^{-1}$ due to $\mathrm{OH}$ stretch of water (The contribution of the protein to the $\mathrm{OH}$ band can be neglected).

From a Raman spectrum the ratio $R=I_{w} / I_{p}$ was measured. It may be assumed that $m_{p}=a_{1} . I_{p}$ and $m_{w}=a_{2} . I_{w}$, where $a_{1}$ and $a_{2}$ are constants dependent on the Raman differential cross section of the protein $\mathrm{CH}$ vibration and the water $\mathrm{OH}$ vibration respectively. Because the lens consists of $98 \%$ of water and protein it is evident that:

$$
\begin{gathered}
\frac{P}{100 \%}=\frac{m_{p}}{m_{p}+m_{w}}=\frac{a_{1} I_{p}}{a_{1} I_{p}+a_{2} I_{w}}=\frac{1}{1+A \cdot R}, \text { where } A=\frac{a_{2}}{a_{1}}, \\
\text { thus } \frac{100 \%}{P}=1+A . R .
\end{gathered}
$$

We determined the value of $A$ by measuring $R$ from solutions with known protein concentrations. In this study, bovine serum albumin (purity $98.6 \%$ ) obtained from Sigma was used. Concentrations ranging from 10 to $35 \%$ were measured. Higher concentrations 


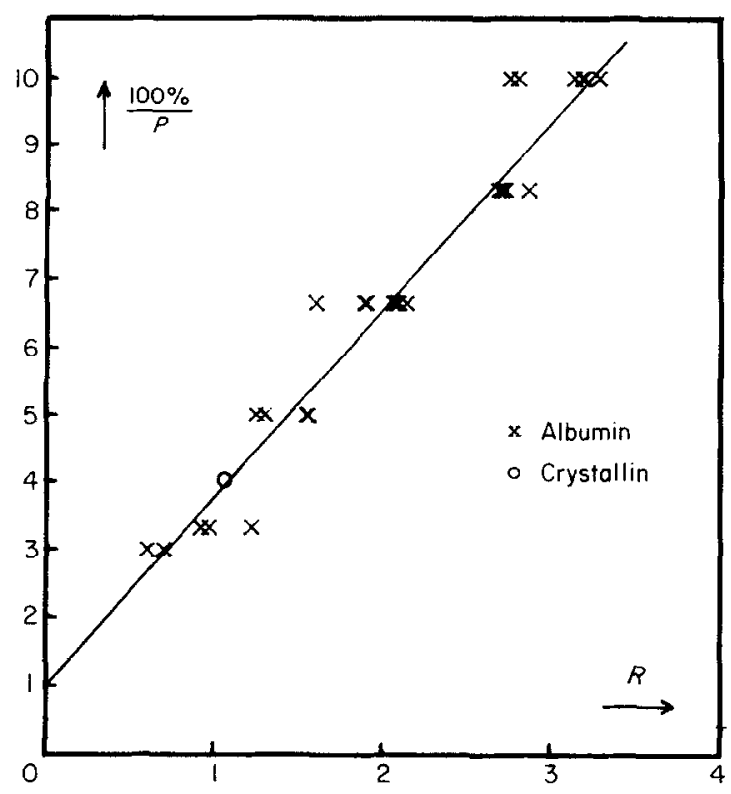

Fio. 1. Inverse of the protein mass percentage as a function of the ratio $R$ for crystallin and albumin solutions. The straight line represents a first-order least-square polynomial that has been fitted to the data points.

were excluded because of the limited solubility of albumin. Concentrations lower than $10 \%$ were not included because the intensity of the CH Raman band of protein becomes so low compared to the $\mathrm{OH}$ band of water that the error in the ratio $R$ becomes too high. From the spectra the ratio $R$ was calculated and plotted against the inverse of the protein mass percentage $(100 \% / P)$. The relation between $100 \% / P$ and $R$ proved to be linear (Fig. 1) as was expected on account of formula (1). With a least-square analysis the value of $A$ was calculated. A control measurement was also made with a $25 \%$ solution of extracted and lyophilized rabbit lens crystallins kindly provided by Professor $H$. Bloemendal. The obtained value for the coefficient $A$ is $2 \cdot 8$ with a standard deviation of $0 \cdot 1$. The ratios $R$ found for the rabbit and human eye lenses were converted to absolute water mass percentages using :

$$
W=\left(1-\frac{1}{1+A R}\right) \cdot 100 \% .
$$

\section{Results}

Figure 2(b) shows the ratio $R$ along the visual axis of four intact fresh rabbit lenses. Figure 2(a) shows how this ratio was calculated from the Raman spectrum. The background was estimated according to the dashed line in Fig. 2(a).

A slight difference between the lenses of the two rabbits can be seen. In the cortex the two lenses of rabbit 1 show a smaller value for the ratio $R$ than the two lenses of rabbit 2 . This must be due to an individual variation in water content.

The absolute water content was calculated along the visual axis in 4 intact fresh, four intact fixed and four sliced rabbit lenses. The results are summarized in Fig. 3. The fresh, fixed and sliced rabbit lenses show a great similarity in water content and gradient. The spreading in the data points (deviation from a 'mean curve') is less for the intact fixed lenses than for the fresh lenses. 


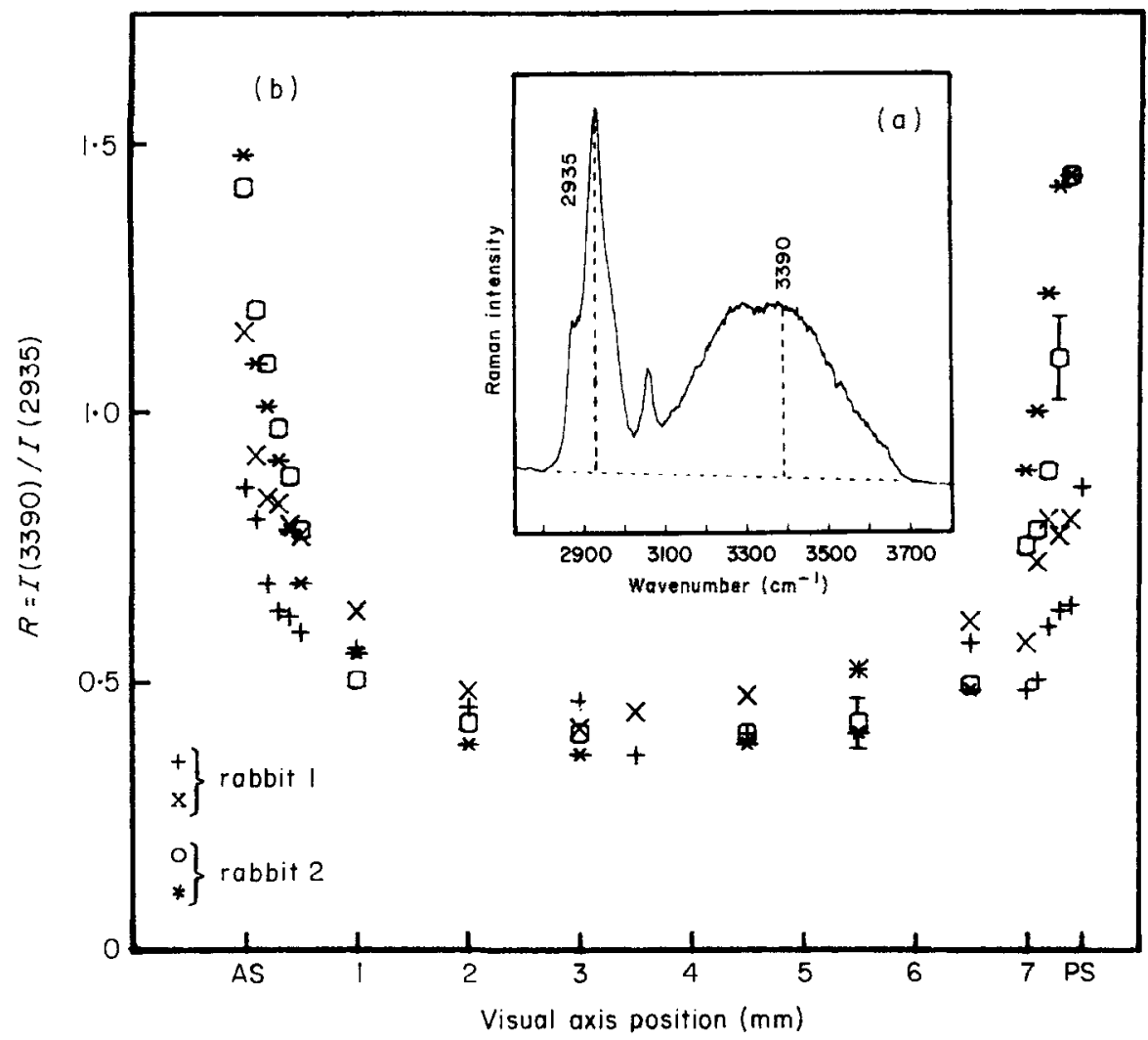

Fir. 2. (a) Raman speetrum of an intact fresh rabbit lens in the nuclear region. Instrumental conditions: laser power at sample $25 \mathrm{~mW}$, excitation wavelength $514.5 \mathrm{~nm}$, resolution $4 \mathrm{~cm}^{-1}$, data integration time $60 \mathrm{sec}$. (b) The relative water to protein ratio $R$ (Raman intensity at $3390 \mathrm{~cm}^{-1}:$ Raman intensity at $2935 \mathrm{~cm}^{-1}$ ) along the visual axis of 4 intact fresh rabbit eye lenses. The 4 lenses $(+, x$ and $\left.0 .{ }^{*}\right)$ were extracted from 2 rabbits. AS : anterior surface, PS: posterior surface.

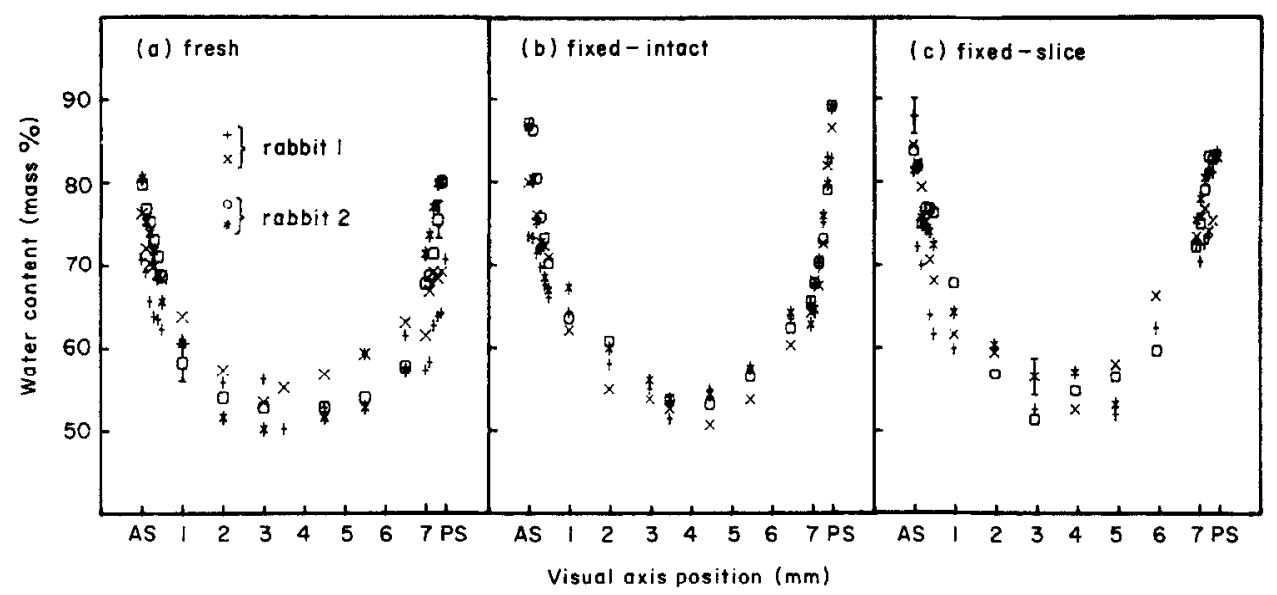

Fic. 3. Comparison of the absolute water content along the visual axis for intact fresh rabbit lenses (a). intact fixed rabbit lenses (b) and slices of fixed rabbit lenses (c). Symbols used in all 3 figures are the same as in Fig. 1b. 

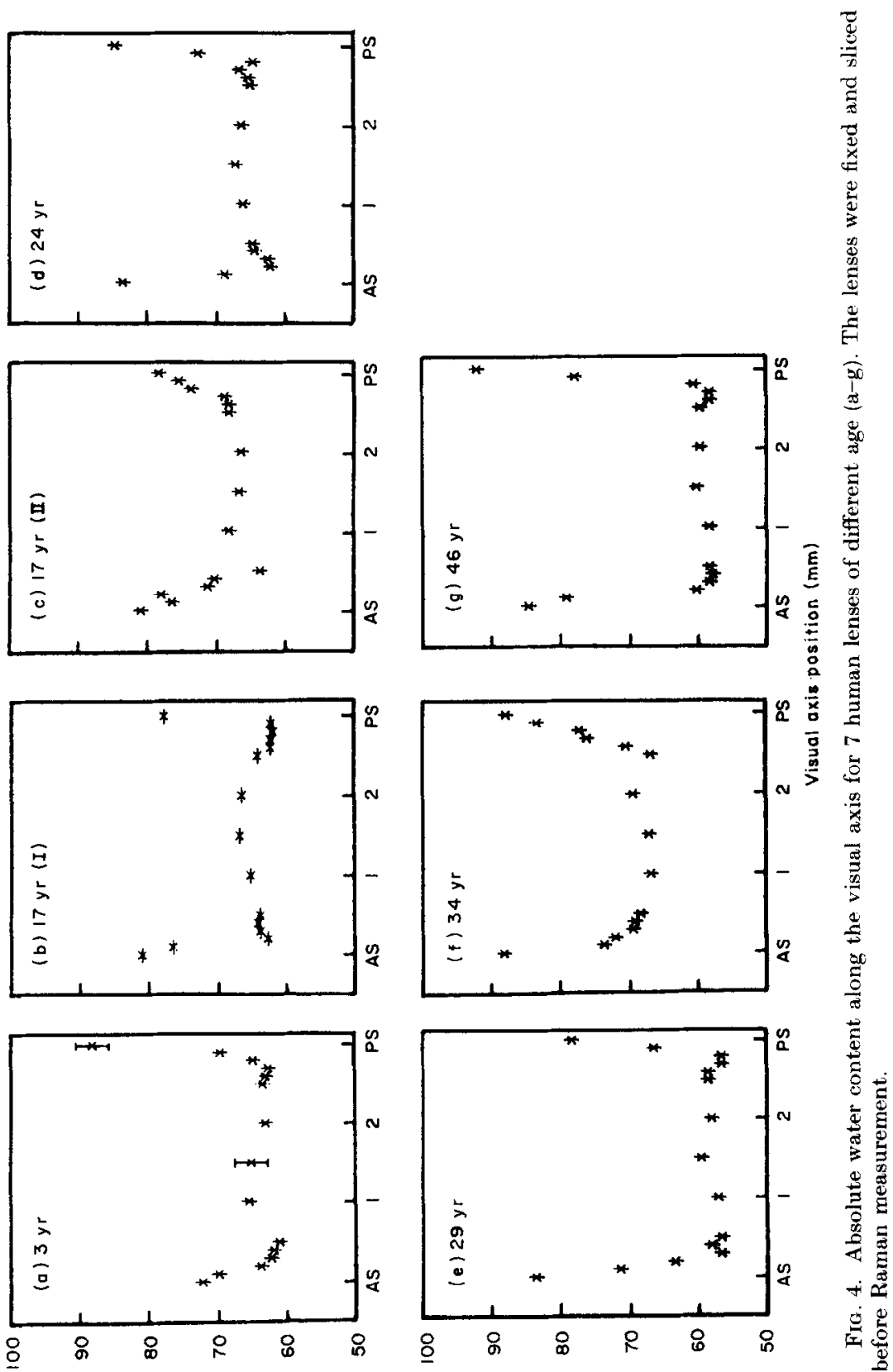

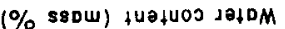


The error in $W$ was calculated by taking into account the estimated error in $R$ only. This resulted in an uncertainty in $W$ of $\pm 2 \%$. The error in the determination of the calibration curve (value of $A$ ) was not taken into account, because this is a systematic error which will shift all found values of $W$ by almost the same amount. An uncertainty of 0.1 in the value of $A$ will give an uncertainty in $W$ of about $1 \%$.

The absolute water content of the rabbit lenses, as given in Fig. 3, is comparable to values given by Hockwin, Rast, Rink, Munninghoff and Twenhöven (1978). For rabbits 6-8 months old, they reported a water content of about 69 and $50 \%$ in the cortex and the nucleus respectively.

Figure $4(a-g)$ shows the absolute water content along the visual axis of 7 human lenses. The measurements were all carried out with fixed lens slices. It can be seen that there is a great variation in water content among individuals. When compared to the results of the rabbit lenses it must be noted that the fall from high water content in the cortex to the nucleus is gradual in the rabbit lenses and steep in the human lenses. For 4 of the human lens slices, measurements were also carried out along the equatorial axis. The results are give in Fig. 5 .

In order to compare our results of the absolute water enntent of human lenses with values given in literature, the mean water content in the nucleus and in the (outer) cortex was calculated. For every lens the mean water content in the cortex was calculated as the mean of 12 values in the outer $0.5 \mathrm{~mm}$ of the lens (along the visual

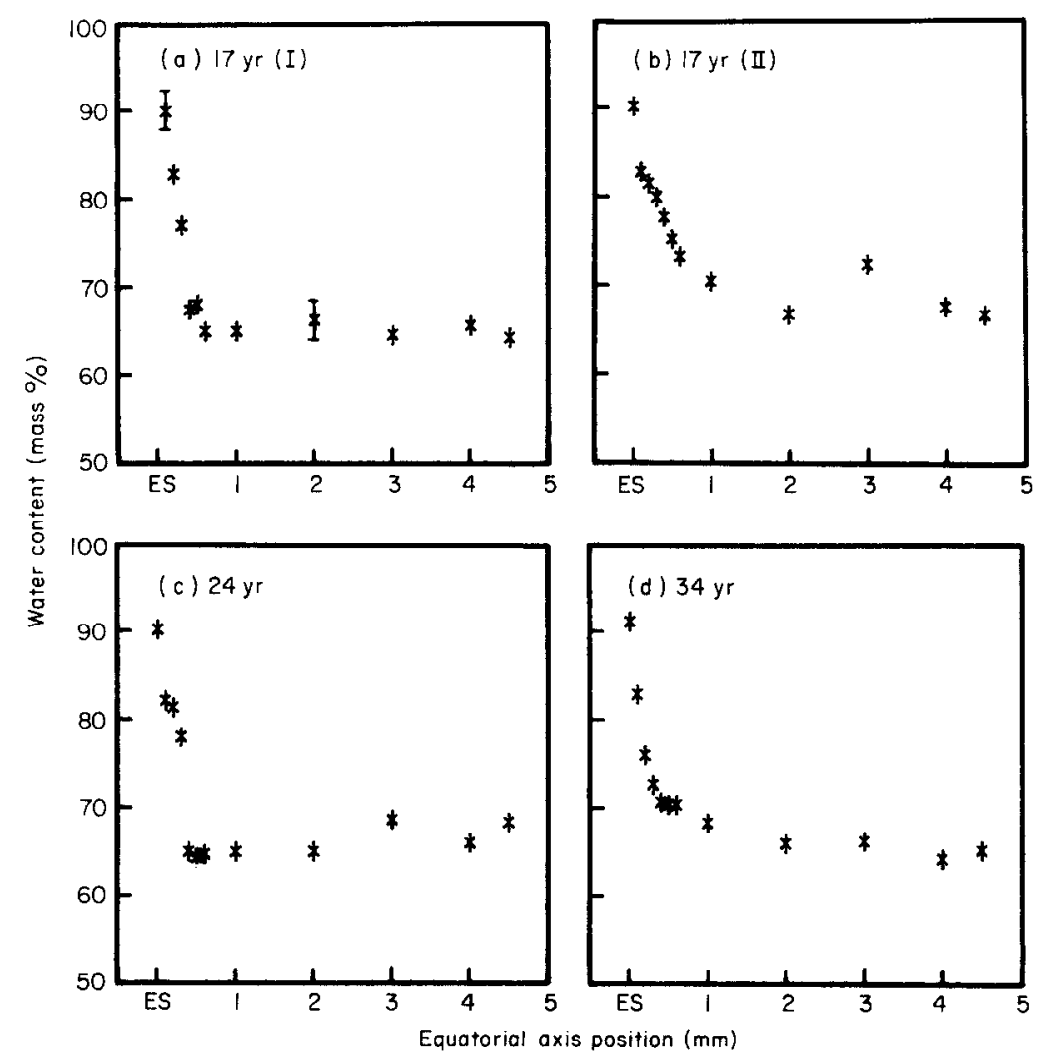

Fia. 5. Absolute water content along the equatorial axis for four human lenses of different age (a-d). The fixed lens slices, used for this measurement, correspond with those in Fig. 4. ES: equatorial surface. 
axis). The mean water content in the nucleus was calculated as the mean of three values in the inner $1 \mathrm{~mm}$ of the lens (along the visual axis). The mean water content in the nucleus and the cortex obtained for all 7 human lenses were averaged and the result (+s.D.) is shown in Table I. It is clear that our results are in good agreement with the values given in literature. It must be noted that a mean water content for the cortex has not much significance because, as can be seen in Figs 4 and 5, the cortex is an area where a steep gradient in water content exists. This gradient may be physiologically more important than the mean water content.

TABLE I

A survey of measurements of the water content in human lenses

\begin{tabular}{lll}
\hline & \multicolumn{2}{c}{$\begin{array}{c}\text { Water content } \\
\text { (mass\% \% } \% \text { s.D.) }\end{array}$} \\
\cline { 2 - 3 } & Nucleus & Cortex \\
\hline Fischer and Pettet (1973) & $63 \pm 3$ & $69 \pm 4$ \\
Bettelheim et al. (1982) & $61 \pm 7$ & $64 \pm 3$ \\
Ringens et al. (1986) & $65 \pm 1$ & $72 \pm 2$ \\
Bours et al. (1987)* & $65 \pm 2$ & $71 \pm 2$ \\
This study & $65 \pm 4$ & $69 \pm 4$ \\
\hline
\end{tabular}

* Recalculated results of Van Heyningen (1972).

The standard deviation in Table $I$ is not a measure for the accuracy of the method used, but only represents the individual variation in water content of the different human lenses. We believe our method has an accuracy in the absolute water content $W$ of about $3 \%(2 \%$ due to the uncertainty in $R$ and $1 \%$ due to the uncertainty in $A)$.

\section{Discussion}

We correlated the ratio $R$ obtained from the Raman spectrum with the absolute water content using calibration data obtained with albumin solutions. We believe that a calibration curve obtained with albumin solutions can be used for eye lenses which contain $\alpha$-, $\beta$ - and $\gamma$-crystallins. The reasons therefore are as follows.

(i) The data point obtained for the rabbit crystalline solution is in line with those found for albumin (Fig. 1).

(ii) The difference between albumin and crystallins is the value of $a_{1}$, which depends on the Raman differential cross section of the $\mathrm{CH}$ vibration $\left(2935 \mathrm{~cm}^{-1}\right)$ per mass unit protein. For a great number of proteins this value is almost constant.

The fresh, fixed and sliced rabbit lenses show a great similarity in the water content and gradient (Fig. 3). This provides evidence for the fact that neither paraformaldehyde nor slicing influence the water content greatly.

Previously it was shown (Bot et al., 1988) that fixation with paraformaldehyde and slicing do not influence the Raman spectra. It must be concluded that the mean water content in the fixed and sliced lenses in the outer cortex (from 0-0.4 mm) is slightly higher than in the fresh lenses. Probably the outer cortex swells in the 
fixative. This may also account for the fact that a very small peak of cacodylate at $608 \mathrm{~cm}^{-1}$ can be seen in the spectra of the outer cortex (0-0.4 mm) of fixed lenses. Deeper in the lens this cacodylate peak cannot be detected.

It is striking that the water content in the intermediate zone (deep cortical) of the human lenses is lower than in the central nucleus. This phenomenon has not been mentioned so far. We cannot explain the reason for this finding, but it may be noted that in morphological studies (Willekens et al., 1988) early precataractous spots are found particularly in this intermediate zone. Perhaps there is a relationship between the physiological low water content in this zone and early precataractous spots. This remains an interesting question for future studies. The cortex especially shows a great variation in water content per location. A rapid decrease in water content from the outer cortex to the inner cortex may reflect the process of maturation of the young lens fibers in this region.

In the equator the water content seems to be higher than in the anterior or posterior cortex. 'Ihis may also be related to the maturation and differentiation of the newly formed fibers. The water content does not decrease as rapidly as in the anterior or posterior cortex. This again stresses the necessity to make strictly local measurements.

The present paper clearly shows that Raman microspectroscopy allows the measurement of local variations in absolute water content of eye lenses. It has also shown that fixation with paraformaldehyde and subsequent slicing only slightly affects the water content of lenses and the local distribution. For several reasons this is especially important for human lenses: (a) as outlined in a previous paper, reliable spectra of human lenses above the age of $20 \mathrm{yr}$ can only be obtained after slicing and pre-irradiation (Bot et al., 1988) and (b) limited availability of human lenses. The local variation in absolute water content, as illustrated in the present paper, may be an important clue for the etiology of osmotic and senile cataractous turbidities. Differential scanning calorimetry, nuclear magnetic resonance and dynamic light scattering do not allow such precise local measurements of water content. The dryweight/frozen sections technique of Bours et al., (1987) also enables more or less precise local measurement of the water content of lenses. The results of these authors on human lenses are largely comparable with the present Raman measurements. It is rather unlikely, however, that the dry-weight/frozen sections technique allows the analysis of the water content of small $(<1 \mathrm{~mm})$ opaque turbidities in early cataractous lenses.

\section{ACKNOWLEDGMENTS}

We thank Dr E. Pels, head of the CorneaBank Amsterdam, who kindly provided us with human donor lenses. We are indebted to Professor H. Bloemendal from the University of Nijmegen, who gave us the lyophilized lens crystallins. This study was carried out within the framework of the European Economic Community Concerted Action on Cellular Aging and Diseases (Eurage) and was supported by the Netherlands Technology Foundation (STW).

\section{REFERENCES}

Bettelheim, F. A., Ali, S., White, O. and Chylack, L. T. (1986). Freezable and nonfreezable water content of cataractous human lenses. Invest. Ophthalmol. Vis. Sci. 27, $122-5$.

Bettelheim, F. A., Christian, S. and Lee, L. K. (1982). Differential scanning calorimetric measurements on human lenses. Curr. Eye Res. 2, 803-8.

Bot, A., Vrensen, G., de Mul, F. and Willekens, B. (1988). Positions defined water content of human and rabbit lenses, a Raman microspectroscopic investigation. Ophthalmic Res. 20. 93 . 
Bours. J. and Födisch, H. J. (1986). Human fetal lens: wet and dry weight with increasing gestational age. Ophthalmic Res. 18, 363-8.

Bours, J., Födisch, H. J. and Hockwin, O. (1987). Age related changes in water and crystallin content of the fetal and adult human lens. demonstrated by a microsectioning technique. Ophthalmic Res. 19.235-9.

Chylack, L. T., Tung, W. and Harding, R. (1986). Sorbitol production in the lens: a means of counteracting glucose derived osmotic stress. Ophthalmic Res. 18, 313-20.

Fischer, R. F. and Pettet, B. F. (1973). Presbyopia and the water content of the human erystalline lens. J. Physiol. 234, 443-7.

Gijsbers, G., Vrensen, G. F. J. M., Willekens, B., Maatman, D., de Mul, F. F. M. and Greve, J. (1986). Raman microspectroscopic investigations of human eye lenses. In Laser Scattering Spectroscopy of Biological Objects. (Eds Stepanek, J., Anzenbacher. P. and Sedlacek. B.). Pp. 583 94. Elsevier: Prague.

Hockwin, O., Rast, F., Rink. H., Munninghoff, J. and Twenhöven, H. (1978). Water content of lenses of different species. Interdiscipl. Topics Geront. 13, 102-8.

Iriyama, K., Mizuno, A.. Ozaki, Y., Itoh, K. and Matsuzaki, H. (1982). An application of laser Raman Spectroscopy to the study of a hereditary cataractous lens; on the Raman band for a diagnostic marker of cataractous signatures. Curr. Eye Res. 2, 489-92.

Lahm, D., Lee, L. K. and Bettelheim. F. A. (1985). Age dependance of freezable and nonfreezable water content of normal human lenses. Invest. Ophthalmol. Vis. Sci. 26 , $1162-5$.

Latina, M., Chylack, L. T., Fagerholm, P., Nishio, I., Tanaka, T. and Palmquist. B. M. (1987). Dynamic light scattering in the intact rabbit lens. Its relation to protein concentration. Invest. Ophthalmol. Vis. Sci. 28, 175-83.

Lerman, S. (1984). Biophysical aspects of corneal and lenticular transparency. Curr. Eye Res. 3. $3-14$.

McEwan, J. and Farnsworth, P. N. (1987). Regional resistivity variations in lens homogenates. Exp. Eye Res. 44, 567-76.

Maraini. G. and Mangili, R. (1973). Differences in proteins and in water balance of the lens in nuclear and cortical types of senile cataract. In The Human Lens in Relation to Cataract (CIBA Foundation Symposium 19). Pp. 80-97. Elsevier: Amsterdam.

Nunnari, J. M., Williams. T. R. and Powell, D. L. (1986). Determination of the state and content of water in human normal and cataractous lenses by differential scanning calorimetry. Ophthalmic Res. 18, 117-24.

Racz, P., Tompa, K. and Pocsik, I. (1979). The state of water in normal and senile cataractous lenses studied by nuclear magnetic resonance. Exp. Eye Res. 28, 129-35.

Ringens, P. J., Bistervels, B., Hoenders. H. J. and Wollensack, J. (1986). Lens proteins in intumescent cataract. Ophthalmic Res. 18, 61-7.

Spector, A. (1984). The search for a solution to senile cataracts. Invest. Ophthalmol. Vis. Sci. 25, $130-40$.

Van Heyningen, R. (1972). The human lens. III. Some observations on the post-mortem lens. Exp. Eye Res. 13, 155-60.

Willekens, B., Kappelhof, J. and Vrensen, G. (1987). Morphology of the aging human lens. Biomicroscopy and Biometrics. Lens Res. 4. 207-30. 